\title{
Toward a Theory of Economic Development as a Mode of Flash Capitalism
}

\author{
Robert Kirsch
}

\section{Introduction}

This article takes up the concept of "flash capitalism" (Agger \& Luke, 2015). As the slow, uneven recovery of the Great Financial Crisis continues, the fact that almost a decade later things are not yet back to "normal" has spawned some handwringing texts by mainstream economists who admit that perhaps all is not well in market society. Piketty's Capital in the Twenty-First Century served as the touchstone of a kind of literature that admitted that widening inequality was a problem in market society, but that some fine-tuning by the federal government could lessen it, restoring some kind of balance between economic growth and the return on capital investment.[1] Agger and Luke argue that Piketty's text confirms capitalism cannot sustain itself under the weight of its internal contradictions, but relies on a deus ex machina of the visible hand of the state to step in and turn things around (Agger \& Luke, 2015, p. 344). They refer to this pivot of diagnosing the ills of capitalism while giving an easily digestible solution that does not transcend capitalism as "blockbuster Marxism." Blockbuster Marxism is not a Marxism that seeks to dialectically transcend capitalism through class struggle in order to establish a free association of workers, but an uncritical (and indeed unspoken Marxism since Piketty and his ilk eschew the term) one in which thoughtful economists realize that perhaps there is a need for the state after all, especially in an era of quick turnover in flash capitalism, where financial loci of buying and selling are untethered from sites of material production, and where speeds of trades are measured in nanoseconds.

This article is a contribution on just how the state becomes visible, where it intervenes, how it intervenes, and to what end in such a regime of flash capitalism. First, a theoretical treatment of the state shows that from Piketty to Minsky, an immanent analysis of the role of the state establishes the underpinnings for the fast and sustained role of state financial intervention in flash capitalism. As a case to show such a role of the state as catalyst of flash capitalism, the next section is an analysis of the United States' Economic Development Administration (EDA). This will be used to show how the state, far from wisely intervening as an external agent to alleviate the periodic crises that result from the ebullience in market society, rather accelerates the cycle of crises. It encourages speculative investment of public funds, and establishes its role as persistent infuser of capital as a necessity pillar of what is often referred to as economic development. The first part deals with the role of the state in orthodox market society, then overlaying the notion of flash capitalism to make more sense of why the state is such an active agent in economic development. The second part takes up the structure of the EDA, in particular how it carves up the United States into Economic Development Districts (EDD), and through the use of annual comprehensive economic development strategies (CEDS) documents, intertwine a reliance on state investment, and maintains that investment in a speculative manner, serving mostly business interests. The final section looks at the 2016 CEDS document of the Central Arizona Governments to see how their investment strategies are geared to be speculative toward business interests, especially the financial churn of the financial presence of Maricopa County, and how there is little evidence that EDA investment achieves its goals of building better communities. The final analysis shows 
that flash capitalism is an appropriate theoretical lens to view EDA intervention into EDD and CEDS funding; one that does not assume the wise intervention of liberal economists like Piketty and Minsky for good governance, but as the logical conclusion of a speculative churn where the intense speed of financial turnover entices businesses and economic development regions alike to attempt to strike it rich.

\section{The Role of the State in Flash Capitalism}

Before assessing what the state looks like in flash capitalism, it is important to get a sense of what the economic orthodoxy considers the ontological and practical role of the state. As discussed above, Piketty's supposedly provocative conclusion is that the state should levy some kind of wealth tax to reduce inequality in order to bring it closer in relation to the overall rate of economic growth. How this is to be accomplished is not discussed, except to note that it is difficult, and "...requires a high level of international cooperation and regional political integration," adding the speculative punch that we should “... bet everything on democracy" (Piketty, 2014, p. 573). Apparently even a somber commitment to a mode of government is best conceived of in speculative terms.

It is perhaps a peculiarity of economics as a discipline that treats the state as an opaque monolith with an on/off switch, whose job it is to wait in the wings until things become sufficiently degraded to step in and force cooperation and integration at an inter- and subnational level, to say nothing of some of the classical and neoclassical theories that have no conception of the role of the state at all. Again using Piketty as an example, his text talks about "the state" in numerous places in many predictable ways, such as the welfare state of post-World War II and the Thatcher/Reagan state of deregulation afterward. But in the latter half of the book, he makes a shift to discuss the "social state," which is apparently when the state pursues the kinds of programs with its revenues of which Piketty approves (Piketty, 2014, p. 477). Agger and Luke point out that this is more than just analytical ambiguity, but an attempt to dance around the baggage of the caricature of his own making that is state socialism (2015, p. 344). This unwillingness to engage in the existing historical alternatives to capitalism is most likely what propelled Piketty to his celebrity status, even if it amounts to nothing more than a vague plea for an interventionist state with a human face. It walks the tightrope of pointing out the grave ills of market society while simultaneously calling for a minor tweak in the fiscal policy as a solution to those same grave ills. This uncritical critique is "blockbuster Marxism," that does not investigate the internal contradictions of market society (2015). In other words, Piketty seems to dream of a state that does its job as an external fixer, but just a little bit better.

The idea that the state exists as an external salve that can swoop in and save the day when things go haywire is a relatively common position in economics discourse, and most discussions of state activity revolve around when and how much the state should intervene, not whether it should at all. While Piketty does not mention Minsky by name in his blockbuster, Minsky's positioning of the state as the visible hand that undoes the damage of the invisible hand of the market fits in nicely with a vision of the role of the state as what Minsky called the "lender of last resort" (Minsky, 2008). Minsky's analysis here will serve as a bridge between Piketty's blockbuster Marxism of the social state, and Agger and Luke's theory from a Marxist perspective of flash capitalism. The basis of this bridge is in Minsky's "Financial Instability Hypothesis" (FIH) that establishes financial instability and state response as an endogenous process of capital accumulation. This is contrary to more mainstream economic theories of state intervention in market society, but Minsky saw that (perhaps in part because of his time as a student of Joseph Schumpeter) the state did not simply step in to mop up the financial messes of market society when some exogenous shock caused a recession. Instead, he saw financial fragility as an endogenously created phenomenon, under the notion that "stability is destabilizing" (Minsky, 2008, p. xii). That is, the relative calm of stable accumulation encourages economic actors to take risks that will ultimately destabilize the financial system and require state intervention; that this is a general condition of accumulation in financial capitalism.

The FIH posits two premises: "Capitalist market mechanisms cannot lead to a sustained, stable-priced, fullemployment equilibrium," and "Serious business cycles are due to financial attributes that are essential to capitalism" (Minsky, 2008, p. 194). These postulates clearly make room for the state to intervene where the market cannot fulfill certain objectives, such as full employment. The unravelling of a stable financial system to an unstable one, according to the FIH, is as follows: A period of what Minsky calls "hedge finance" is the most stable, where firms have enough cash on hand to meet its payment obligations, and keeps assets on the side in case of a market downturn (Minsky, 2008, p. 372). The conditions of hedge finance create a level of confidence for investors that leads to the next stage, 
“speculative finance.” Investments are routinely valorized, and firms are emboldened to seek higher returns in riskier investments. The hallmark of speculative finance is that firms do not necessarily have the cash on hand to meet their payment obligations, but loans are easy to get, because confidence runs high and interest rates are low (Minsky, 2008, p. 373). Eventually, the confidence wears off, and lenders start calling in their loans, either because of a decrease of confidence in the ability of firms to repay, or because Federal Reserve interest rates are increasing. Firms, without the cash on hand to meet their obligations, go further into debt to service the debt they already have. Minsky refers to this stage of instability as "Ponzi finance" (Minsky, 2008, p. 377). Much like the fraud for which it is named, this stage of financial instability is characterized by firms using fresh cash from new investors to fulfill their payment obligations to their older investors. Eventually, new investors wise up and stop lending, and firms are unable to meet their payment obligations. An example from the Great Financial Crisis is the commercial paper freeze-up, leaving many firms unable to meet any of their payment obligations, even payroll. At this point, Minsky argues that only the state has the fiscal capacity to step in and make firms whole again. But instead of reestablishing a new equilibrium to be maintained, Minsky argues this simply starts the cycle over again; when the state props up asset prices to maintain profits, that gets the economy back to a hedge position, but it does not stop the process whereby instability emerges. Eventually the new hedge finance will encourage speculation.

The insight about the instability of capitalism and the role of the state as salve for as well as cause of that instability gave Minsky his own moment of fame in the immediate aftermath of the Great Financial Crisis, even if his moment was nothing like Piketty's. However, there is a compelling logic to Minsky's argument: after the disaster of a non-intervening state in the Great Depression (and the numerous crunches, crises, and crashes before), the state's involvement in and after World War II set up a stable capitalism, but Minsky understood the cyclical dynamism of financial capitalism. Minsky chides those who think that this postwar capitalism is an ideal standard to which we must attempt to return and then freeze in place. He notes only that while the period of 1945-1965 was the best-performing example of financial capitalism, it was only a "practical best" that set the stage for further instability (Minsky, 1993, p. 3). That further instability began emerging around the mid-1960s when bank rescues became increasingly common, and more financial actors needed state intervention to sustain business profits and ward off recession (Minsky, 1982). With subsequent crises in the energy sector in the 1970s, and increasing fragility of the Finance, Insurance, and Real Estate (FIRE) sector of the economy in the 1980s and early 1990s, the stability from the practical best provided the grounds for a sprawling instability in the economy more broadly. The duration, location, and frequency of state intervention have all ramped up since the end of this practical best, and the economic sectors that receive state intervention to prop up profits then operate under the assumption that the state will bail them out, making the restored financial stability, once again, unstable (Minsky, 1982, p. 194). Such a result intensifies and compresses the cycles of financial instability. Minsky's diagnosis is that such instability, being inherent to a capitalist economy, can only be constrained by the Federal Reserve's ability to set floors and ceilings on that instability; essentially proposing a wise administration of central bankers (Schumpeter referred to wise bankers as ephors, protecting society in the interest of capital accumulation) to soften the peaks and valleys of instability. The state sets a floor through its ability to refinance assets at a price of its choosing, regardless of their market value (this is its bailout function), and it sets a ceiling by raising interest rates in an attempt to discourage speculation by making it a more costly endeavor (Minsky, 2008, pp. 48-49).

Minsky offers a path for what is to be done by appealing to what he refers to as the "Keynesian-Rooseveltian policy synthesis" (Minsky, 1981, p. 49). Contrary to the assumption that the effectiveness of the New Deal was due to a system of transfer payments and social insurance programs, Minsky argues that the most effective programs were the ones that constrained financial speculation, and that focused on full employment schemes (Minsky, 1981). This wise administration of income allocation and investment was what Minsky saw as a path to placing the ceilings and floors on financial instability. This insight also sheds light on a direct connection to Marxian analysis. Minsky argues that Keynes, and by extension twentieth century Keynesianism, can be understood as a conservative Marxist who is pro-capitalist because his analysis uncovered the internal and endogenously-produced contradictions of financial capitalism without Marx’s "pejorative" element (Minsky, 1981, p. 54). Here is where we complete the bridge that Minksy provides from Piketty to flash capitalism. Whereas Piketty conceives of the role of the state as an external force that can provide just-in-time fixes when financial returns outpace growth, Minsky showed that the role of the state has to be conceived of endogenously in order to manage financial instability, just like the crises which it addresses are endogenous.

The perspective of flash capitalism highlights how Minsky's prescription of wise fiscal policy to be administered ultimately does not follow from his own logic. Minsky believed that capitalism could be properly administered so as to 
minimize its internal contradiction through proper policy. If, however, the contradictions are never transcended, and the fixes that wise policy provides can only set the stage for future instability, it makes rather more sense to conclude that the policy enacted itself becomes a catalyst of instability. This is an immanent critique positing that the state, via fiscal policy, maintains the churn of financial accumulation, and its concurrent instability. The result would be more frequent and more intense downturns, as well as more intense and ephemeral booms. Where both Piketty and Minsky draw an untenable conclusion that can only deal with the consequences, not the causes of instability (Agger \& Luke, 2015, p. 341), flash capitalism provides better insight: the state becomes an enabler of the flash, desperately maintaining the valorization process through its increasingly necessary and increasingly intense interventions.

It is an important insight of flash capitalism that the speed and intensity of processes of accumulation is a better way of apprehending the dynamism of social processes. This gets past Piketty's wish for better tax policy, and Minsky's wish of wise administration, to conclude that instead of the state stepping in to tamp down the intensity of instability, it instead has an interest in participating in that instability to maintain capital valorization, inexorably fueling the same instability. Agger and Luke note this function of the state as a legitimating intervention that maintains the value of its unit of currency (338). The necessity of the state's sovereign action in order to maintain value of money and to keep capital accumulation continuing apace firmly situates flash capitalism in a Marxian tradition. Marx says, "The business of coining, like the establishing of a standard measure of prices, is an attribute proper to the state" (Marx, 1992, pp. 221-222). Using interest rates to cool speculation or to refinance distressed assets in order to make investors whole is similarly an attribute proper to the state. The result is that the role of the state is not simply to name the unit of account, but to participate in the process of valorizing that currency through sovereign fiscal intervention. If flash capitalism's speculative churn is the name of the game, then the state props that up via its sovereign authority to legitimize those social relations, even when they are disastrous. The real consequence that flash capitalism provides as a result of the Financial Instability Hypothesis is that the state is a catalyst for, not an external force against, frequent and deep financial instability. The next section will explore an explicit example of how the state acts as a catalyst for speculative churn.

\section{The Economic Development Administration}

While the preceding section establishes the state as an internal accelerant of flash capitalism, it is not necessarily thought of in such a way. This section will deal with the United States Economic Development Administration (EDA) to highlight how it conceives of itself and what it does, its mission of economic development as opposed to economic growth, and how it evaluates the outcomes of the programs it funds. Doing so will show how it is an accelerant of flash capitalism as opposed to a wise investor or manager in community development.

The EDA was established in 1965 to spur economic and community development in regions throughout the United States. The year is important because it is in the tail end of Minsky's "practical best," as the onset of speculative finance made the financial system more unstable. It makes historical sense why that a piece of legislation codifying state intervention to ameliorate that instability and protect regions from the consequences of that instability emerged when it did. The thrust of the legislation carves up the United States into Economic Development Districts (EDD), which are usually clusters of contiguous counties (though there are provisions for Indian Tribes and university research centers, too) that have a per capita income of 80 percent or lower of the national and/or an unemployment rate that is at least 1 percent above the national average (Public Works and Economic Development Act of 1965, 1965, p. 14). The counties are the most important unit because they file annual Comprehensive Economic Development Strategies (CEDS). CEDS are essentially federal grants that keep the EDA apprised of past present and future opportunities of economic development, specific strategies of transportation, business, or environmental protection that could be had, and how granted projects will improve economic prospects of the EDD (1965, p. 14). To put CEDS in terms of flash capitalism, they represent a documentation of the churn of the evolution of areas where a federal infusion of capital is requested.

It is especially noteworthy that the piece of legislation itself notes that incomes and employment are not evenly spread out, due to things like base closures, natural disasters, and outmigration, all of which necessitates federal economic intervention (1965, p.4). The act reiterates many times that the goal of economic development is to alleviate unemployment. The act further specifies that private-public partnerships are a way to keep economic development local but ensure that those localities can keep up with global technologies (1965, p. 7). The funding mechanism 
is balanced, with Section 204(a) stating that the federal share of a project will be one half $(1965$, p. 9). There are exemptions of course, but the idea here is that the community bears responsibility for its own development, at least in part. To put this in more explicitly financial terms, one could say that this clause guarantees that EDDs have "skin in the game." Regardless, the outcome of funding CEDS projects is supposed to be a joint-effort of the private and federal sector that improves communities, buoys incomes, creates jobs, and gets EDDs back on the map, so to speak.

So far, none of this is out of the ordinary of collaborative governance discourse, although it is mildly surprising that uneven development is so openly discussed. Even so, the EDA seeks to develop local economies without artificially changing the character of those local economies (it of course assumes that this is possible and that localities might otherwise operate independently of larger flows). As the act continues, however, it becomes apparent that this objective is rather difficult to achieve. Take for instance the following clause of the EDA Act: "No financial assistance under this Act shall be extended to any project when the result would be to increase the production of goods, materials, or commodities, or the availability of services or facilities, when there is not sufficient demand for such goods, materials, commodities, services, or facilities, to employ the efficient capacity of existing competitive commercial or industrial enterprises" (p.11). The paradox comes into sharper focus, and carries with it some ideological baggage. There is an assurance here that public funding will not crowd out private capacity, and it further explicitly seeks to avoid the imagined difficulties of overproduction in planned economies. With all that being stipulated, it is not immediately apparent how the federal government will be able to spur development without increasing the production of and demand for goods, materials, etc. That is, if economic regions are in a persistent depressed state of high labor underutilization (i.e. unemployment), economic development would have to increase the demand for that commodity at the very least, as well as the incomes to purchase those commodities. There is no sense that the EDA simply conceives of economic development as simply driving up demand, but it suggests that until that boost in demand happens, it should not act. Below is an analysis of whether the EDA achieves this development-but-notgrowth, but for now this is a tidy way to ignore the tension between growth and development. The cycle of persistent unemployment and its detrimental effect on workers being able to demand and/or consume what is being produced may seem obvious in a Marxian register, but the result of this proviso is a rather peculiar treatment of economic development that is separate from economic growth, but in a way that pits the two concepts against each other.

To sidestep this apparent contradiction requires some doing, but the result is that the EDA does not see itself as an engine of economic growth, but only of economic development. The EDA recently funded a white paper that attempts to define what economic development is, and how it is distinct from economic growth (Feldman, Hadjimichael, Kemeny, \& Lanahan, 2014). Apparently, the inability to properly distinguish between the two leads to a "confused" policy debate, and renders us unable to come to a "clear and shared understanding" of what economic development means $(2014$, p.1). The distinction they offer is worth quoting at length:

While economic growth is simply an increase in aggregate output, economic development is concerned with quality improvements, the introduction of new goods and services, risk mitigation and the dynamics of innovation and entrepreneurship. Economic development is about positioning the economy on a higher growth trajectory. Of the two, economic development is less uniquely a function of market forces... It is within the purview of government (p. 1.).

While the government probably does not need a blessing from professional economists to determine its realm of action, this definition is nevertheless anything but clear and shared. Even ignoring the obvious relationship between increasing aggregate output and the need for improved infrastructure in order to do so, the authors explicitly state that development puts local economies on a higher growth trajectory, making the distinction harder to maintain. It stands to reason that the whole point of development is to get that increase in aggregate output, or else there's no reason to track it. This absurdity comes into starker relief when discussing jobs. The authors also argue that jobs are an example of their distinction; economic growth measures the number of jobs and economic development tracks "wages, career advancement opportunities, and working conditions" (p. 1). If this distinction is held up, then any analysis of jobs that delinks them from wages, mobility, conditions, etc. is obviously impoverished, and renders economic growth a worthless category. Clearly, these two concepts of growth and development are related, but even more important, the idea of a growth trajectory in development can be read as the state goosing local economies to grow through their investments. Regardless of whether the state invests effectively, spurring investment through grant funding has a speculative character with the desired goal of economic growth at the end. However, by delinking the concept of growth from development, the speculative churn of federal investment can continue apace, and the onus for showing that these CEDS projects led to the goals stated can be deferred, perhaps indefinitely as will be shown below. 
Flash capitalism is fast, and the structure and goals of the EDA show no different. The churn is quick, (re) investments are continually assessed and remade through annual CEDS reporting, and the foamy layer of opportunity in development is constantly valorized through federal investment to keep up the pace. Growth can be measured, changed, or otherwise assessed; but by ignoring growth for the more ephemeral economic development, regions can always maintain a need for more federal intervention, to achieve a host to a number of measures, such as quality of life indicators and environmental metrics (p.5). There are always more projects that need funding, and with the money already blocked out in grants in the legislation, that flash has to go somewhere. When looking at the EDA through the lens of flash capitalism, the process of constant intervention as state valorization becomes clear. Instead of economic development becoming a one-shot boost to get communities back on the playing field, ready to compete in a lean and mean global market, Feldman et al are quick to point out the ongoing process of economic development. They note that economic development should not be associated simply with eradicating poverty, but warn that "all regions are vulnerable to economic restructuring and need to consider how to adapt to the changing economy. Places once prosperous have been humbled by international competition... Even places currently doing well realize their economic base could quickly evaporate, leaving them insecure about future prospects. Continual restructuring is the new norm..." (Feldman et al, p. 2). All this because the loci of production are no longer based on regional resources, and the knowledge economy can pop up anywhere, at any time, and so "the concept of economic development is now relevant to the full range of nations, places and communities" (p. 2). They continue that economic development is the sine qua non of the good life, that prosperity and quality of life can only be provided via economic development (p. 19). The EDA Act itself echoes the need for community assistance via constant intervention that is performed under the guise of an ever-present need for intervention, in a section on economic adjustment, where the Secretary of Commerce may provide extra grants to meet special needs that come from "actual or threatened severe unemployment; or economic adjustment problems resulting from severe change in economic conditions" [emphasis added] (Public Works and Economic Development Act of 1965, 1965, p. 12). Indeed, the continual monitoring, intervention, reinvestment, and the flash of quick capital from the federal state to make sure regions and clusters can be prepared for economic downturns (even if only perceived) is perceived of as an essential component of Eudaimonia (Feldman et al, p. 20).

In a regime of flash capitalism, this same dynamic shows the unresolved contradiction of capital accumulation and the desperate attempts to valorize accumulation through state investment. As such, the end result does not matter as much as maintaining the speed of the process of intervention itself. Even though the EDA conceives of itself as the public half of a private-public partnership that leads to thriving EDDs that are able to catch up to the national average in some economic indicators, what remains to be seen is whether and how these objectives are achieved through the wisdom of CEDS investments. That is, if the end result of this process is supposed to be the Eudaimonia of local communities, then surely the EDA submits itself to routine and deep evaluation and assessment from communities in the EDDs in order to measure the quality of life indicators, employment, innovation, and all of the other qualitative markers that economic development can supposedly capture outside of simple "growth" categories. If, on the other hand, the EDA only assesses CEDS for their predictive quality of how to identify funding projects, then this strengthens the flash capitalism thesis of the need for state involvement to continually valorize an otherwise crisis-ridden system of capital accumulation to keep the economic engines moving.

It is a common lament of development scholarship that there is a lack of any empirical evidence of whether economic development strategies actually achieve their stated goals (Reese \& Fasenfest, 2003; Watts et al., 2011). Part of this is surely because of the more abstract and qualitative measures that are supposedly different from growth, but even if this is true, there is a contradiction between the stated goals of the EDA, and what is happening in the communities themselves. In a study funded by the EDA, they were upfront that they were, “...not interested in developing an approach for evaluating completed projects but instead waned a tool that could provide a formative or predictive assessment of how a proposed project might fare before it was even selected" (Watts et al., 2011, p. 66). While other EDA-funded studies suggest that that the community outcomes are indeed important, the real thing the EDA is interested in the process of CEDS planning, noting that ".. so much of the value of the plan lies in the process itself and the extent to which the plan actually comes to fruition" (Reese \& Fasenfest, 2003, p. 266). These two studies under consideration here are supposed to develop instruments to empirically measure economic development, but there are two key flaws. In Watts et al, the methodology is flawed and assumes that CEDS funding works before it collects any data. In Reese \& Fasenfest, the assessment is based purely on the perceptions of CEDS participants, and not only measurable outcomes. Discussing these in turn will show how even with (or indeed as a result of) these limitations, their conclusions strengthen a Pikettian blockbuster Marxism that seeks to remedy the 
ravages of capitalism with wise management of public-private partnerships, in a way that forecloses on the more critical analysis from the vantage of flash capitalism.

Watts et al. assumes that the "EDA public works investments have a positive and measurable economic impact in the communities in which they occur" (Watts et al., 2011, p. 67). They admit that this point is not a given, but continue anyway. This is somewhat surprising because in their assessment of development literature, they find that there is very little evidence for aggregate success of EDA programs. While the flash of state funding does show some boost to employment, the impact they have on incomes is much more ambiguous (Watts et al., 2011, p. 68). The authors believe that maybe the uneven effects of flash development helps with mobility, this is not necessarily clear, and pin their hopes on "industrial cluster theory" (Watts et al., 2011, p. 68). Industrial cluster, however, is just development bluster, and assumes that if there is enough economic activity emanating from areas surrounding the EDDs, then adding one job near an EDD will add .4 jobs in other parts of the district (Watts et al., 2011). To put this in terms of flash capitalism, the flash from state capital infusion hopefully ripples through the district, conjuring marginal returns of along the way.

Because the article starts off with the assumption that EDA investment achieves its objectives of community enrichment and that the EDA is only concerned with the predictive power of CEDS projects, it is not surprising that their article focuses on how EDA grants can best be sought. The authors present a list of findings, but they can be summed up that the best performing CEDS are the ones that need federal intervention the least. That is, EDDs with strong private investment and minimal federal necessity, who display an ability to draw together multiple private capitals have the most long-term sustainable projects (Watts et al., 2011, p. 74). This may be true, but it then belies the reason that EDDs are established in the legislation discussed above. The whole reason that EDDs are eligible for state capital infusion is precisely because private capitals are lacking, employment is depressed, and incomes are low. It is not a very satisfying finding that the most successful EDDs are the ones that might disqualify them from being EDDs in the first place. On the other hand, if the goal of flash capitalism is to find worthwhile projects to create bonanzas, then this is a perfectly germane piece, it just does not seem to adhere to the stated goals the EDA has. If projects are geared only toward those which are fundable to continue securing federal money, then a cycle emerges where an EDD puts up half of the money for a project that is assessed only on its renewable fundability and not whether it makes an appreciable difference in the lives of the communities in that district.

In Reese and Fasenfast, some of the same questions emerge, such as what makes a CEDS grant successful? Again, with this study, the EDA was not concerned about measuring the outcomes of the grants per se, but about measuring the CEDS documents themselves - how well did they involve community participants, whose interests are served, and what is the perception of success? In the CEDS analyzed, some interesting patterns emerge. Most notable is that there is a perception of very highly detailed strategies for projects (Reese \& Fasenfest, 2003, p. 272), while at the same time, the composition of CEDS committees very often do not represent the various demographics in the EDDs, in terms of racial/ethnic makeup, education or profession, noting that, " $[\mathrm{t}]$ here were no CEDS committees composed of at least 50\% professional, educational, or diversity members. Sixty-two percent of CEDS committees had no community members at all, $72 \%$ had no diversity in membership, $60 \%$ had no educational members, $67 \%$ had no economic development members, and 75\% had no members from the professions" (p. 270). This is remarkable because it calls into question how CEDS committees that do not represent their communities produce highly detailed strategies for fundable projects that help those same communities that are not being represented (to say nothing of the fact that so many CEDS committees did not have any economic developers on them). Further, when asked if CEDS projects were implemented effectively, half of the community stakeholders in the process simply did not know (p. 272). Less than half of the community stakeholders thought the CEDS projects were effective, though $75 \%$ of CEDS committee members did (p.274). The authors offer the possibility that a key problem of EDA funding is that "...policies do not appear to match needs and goals as closely as would be desired. This appears to be the case at least in part because the availability of funding drives project election more than do abstract goals" (p. 275). Of course, as noted above, the whole notion of economic development is supposedly tied to the "abstract goals" that the EDA refuses to measure.

It is increasingly clear that the involvement of community stakeholders is not important to a well-executed (read: fundable) CEDS project. Having abandoned the pretense that this is what EDA assessments are measuring, it is worthwhile to uncover who are the CEDS committee participants who are giving highly detailed strategies for projects, and in whose interests these projects are being pursued. Reese and Fasenfest have two main findings: 1) business and government interests are overrepresented on CEDS committees, and that other community participants are underrepresented, and 2) CEDS projects are driven by what is most likely to secure funding (p. 277). With these 
insights in mind, it becomes much clearer to see how a disconnect between effective, highly detailed strategies, and a lack of involvement or knowledge of those strategies by members of the community that these documents seek to assist. There is also the obvious problem that there is no reason to conflate fundable projects with what is good for a given community.

The insight that business interests have captured an avenue of social investment, or conflate community interests with its own, is not on its own anything new. Veblen warned as much over one hundred years ago that having the business interests of a managerial class overtake the production interests of a society leads to an irrational allocation of resources and production (Veblen, 1915). That may be a lamentable problem on its own, but it shows the problems of the skin-in-the-game model of economic development offered by the EDA, and how wise investors of Piketty's blockbuster Marxism are not able to stem the tide of flash capitalism - in fact they facilitate it. This discussion of the EDA and how it conceives of its mission, along with how and why it assesses how it does help show the poverty of blockbuster Marxism. The whole point of CEDS is to get federal money and maybe, if the districts are lucky after their 50\% ante, they'll experience a little ripple multiplier from the bonanza. But that's not the stated goal. The clear goal is for business interests to get the federal government and communities to pay for projects, sustaining the churn of capital investment and accumulation. The flash of federal infusion makes this possible, and is a well that can always be dipped into, because of the wild swings of financial instability that makes all places vulnerable.

\section{| The Central Arizona Governments CEDS of 2016}

The city of Phoenix, and its county of Maricopa do not qualify for involvement in an EDD. However, since as noted above, the multiplier of employment that supposedly ripples out means that the EDDs surrounding Phoenix certainly have it in mind as they offer their projects. Phoenix is actually rather unique in its orientation as a hotbed of flash capitalism, from its inception being a place for hucksters and get-rich-quick scam artists to make a buck and then leave (Good, 1990). This makes the surrounding areas an interesting case study to see if a city more or less built on flash capitalism has provided that employment multiplier. By analyzing the Central Arizona Governments (CAG) CEDS draft of 2016, it will become clear that this example of a concrete development plan confirms the critical examination of CEDS assessments above, and that, once again, flash capitalism provides a better lens to see who benefits from development schemes.

CAG is one of three active EDDs in Arizona and is comprised of Pinal and Gila County, bordering Phoenix along the south and east side, respectively. The proximity to Phoenix is prominent in the CEDS projects, especially for Pinal County, which borders both Maricopa and Pima County, where Tucson is located. The CEDS draft for 2016 will be analyzed with two objectives in mind: 1) Who wrote the draft, and 2) Whose interests are served by the projects being proposed. If the analysis above holds, then the CEDS should not include very much on the quality of life for residents, and instead focus on development projects for economic growth that are aligned with regional business interests.

The CAG CEDS committee members are surprisingly inactive. The assessments above noted how many CEDS committees did not have economic developers, educators, industrial representatives, or other community stakeholders. The CAG CEDS is no different. Of the 32 seats on the board, 10 were vacant, and the remaining 22 had 15 public officials, 6 economic development partnerships, and 1 educational institution with no other community stakeholders involved ("Comprehensive Economic Development Strategy: Central Arizona Governments," 2016, p. 5). Most of the CEDS is recapitulation of the data that qualifies these two counties as an EDD: wages are lower than the national average, and unemployment is higher. What is most interesting in this exposition is how CAG sees itself in a global register, it is not a community of different economic areas to get a little infusion of money from the federal government, but rather an explicit commitment to the flash. Take for instance transportation planning. A new Interstate (I-11) which connects Las Vegas, NV and Phoenix may expand to become a CANAMEX corridor, connecting Mexico and British Columbia, and on its way to Nogales, Mexico, could go through the CAG Region (p. 24). Of course, one of the strategies is to lobby to have I-11 constructed. This is not to suggest that having a massive corridor running through the region is somehow bad for the region, but it certainly is a different story than some plucky counties coming together to build up their economic resiliency, and instead trying to make sure that I-11 cuts through this region since it is already in Phoenix anyway.

However, international superhighways notwithstanding, the CAG CEDS is full of very vague assertions about 
its goals. There is talk about shifting away from its historical reliance on mining, and into the "innovation economy," whatever that is (p. 26). As ambiguous as this assertion is, however, it makes perfect sense couched within the analysis above. The CAG Region seems fully aware that economic downturns can strike anywhere at any time, and being innovative is an economic tool that transcends the rural/urban divide, apparently. Even when the CEDS tries to get more concrete, listing goals and objectives (after the obligatory SWOT analysis, of course) do not seem to yield any actionable items. For instance, the goal of "broadband infrastructure" has two objectives: "provide resilient/ redundant broadband networks within communities" and "explore variety of broadband distribution methods for last mile connections" (p. 34). This is probably a good thing, but it is unclear how a citizen of Pinal or Gila County would know just how they were going to get internet. It seems more likely that these objectives may make more concrete sense to the business community about how businesses are lured and established in certain areas, especially with the help of an infusion of public money. At any rate, these objectives try to take advantage of the population explosion that is happening in the sunbelt. It remains to be seen if that alone is enough to sustain development.

There is a mention of quality of life in these goals and objectives. The goal is to "maintain existing quality of life and utilize current assets to attract visitors" with the objectives to achieve that goal being to "create a coordinated effort to attract visitors to the region" and "preserve character of communities by preserving heritage" (p. 35). Essentially, enhancing the quality of life for residents of the CAG region is to bolster tourism dollars coming in. There are no other action items related to quality of life. The CEDS ends with a list of projects and their costs. They run a gamut from construction of community kitchens, to downtown renovation and revitalization projects. Again, the goal here is not to establish the desirability of these items, but to note that the vast majority of the projects seem to benefit business interests, to facilitate commerce or tourism through roads, bypasses and interchanges. If Phoenix has been a hot spot for people to experience the flash and get out before the crash, the CAG CEDS seems to be positioning itself as flash-adjacent, and trying to invite people to the party. At any rate, the CAG Region CEDS does not seem to be a result of collaborative governance with representative input from numerous community organizations and stakeholders, and is instead proposing what seems fundable, as the analysis above would indicate.

\section{Conclusion}

This article contributed to a critique of the blockbuster Marxism of liberal economists like Thomas Piketty, and in so doing contribute to building a theory of flash capitalism. Doing so meant first recognizing that Minsky was correct that the state was not only a corrective to financial instability, but also an agent of the same cycle of instability. It also means, pace Minsky, that the conclusion we should draw is not that the wise administration of fiscal policy can contain instability. Rather, that participation inexorably accelerates and deepens instability and crisis, since the state must devote itself to facilitating accumulation at all costs. This hallmark of flash capitalism can be seen in how the EDA administers its economic development grants. By giving half funding for the projects, it compels EDDs to put some skin in the development game and chase dollars, hoping to get a boost in income as a result. Projects that get funded are projects that look most fundable, making a feedback loop in the process of putting CEDS together that ignores the communities they seek to avoid, and instead focuses on the business interests of development districts that are devoted to accumulation. The CAG Region is no different.

Joseph Schumpeter had faith in central bankers, and with his usual rhetorical flair referred to them as "ephors." Much like the ephors of Sparta, in Schumpeter's mind, central bankers were devoted to the good of the nation, and should manage fiscal policy wisely on the nation's behalf. We know better than to think that now, and while central bankers are certainly not the wise administrators that we might hope to have, neither, in a regime of flash capitalism, are district planners, angling for the flash to come their way. 


\section{Endnotes}

1. The celebrity status Piketty achieve is hard to understate. For instance, Bloomberg Businessweek made a teen idol style magazine cover featuring Piketty, where he is referred to as "Karl Marx's New Crush." http://assets.bwbx.io/images/users/iqjWHBFdfxIU/ i7daZ5ourC3c/v1/-1x-1.jpg

\section{References}

Agger, B., \& Luke, T. W. (2015). Blockbuster Marxism. Critical Sociology, 41(2), 335-348. https://doi. org/10.1177/0896920514564089

Comprehensive Economic Development Strategy: Central Arizona Governments. (2016). Retrieved from http:// www.cagaz.org/Departments/economicdev/files/ DRAFTCEDS_2016.pdf

Feldman, M., Hadjimichael, T., Kemeny, T., \& Lanahan, L. (2014). Economic Development: A Definition and Model for Investment (EDA Research Report). Retrieved from https:// www.eda.gov/tools/files/research-reports/investment-definition-model.pdf

Good, T. (1990). Phoenix Rising: Explosive Growth in the Sun Belt. In M. Davis, S. Hiatt, M. Kennedy, S. Ruddick, \& M. Sprinker (Eds.), Fire in the Hearth: The Radical Politics of Place in America . London; New York: Verso.

Marx, K. (1992). Capital: Volume 1: A Critique of Political Economy . Penguin Classics.

Minsky, H. P. (1981). The Breakdown of the 1960s Policy Synthesis. Telos, 50, 49-58.

Minsky, H. P. (1982). Can "It" Happen Again?: Essays on Instability and Finance. M.E. Sharpe.

Minsky, H. P. (1993, April 29). The Economic Problem at the End of the Second Millennium: Creating Capitalism, Reforming Capitalism, Making Capitalism Work. Hyman P. Minsky Archive. Paper 101. Retrieved from http://digitalcommons. bard.edu/hm_archive/101
Minsky, H. P. (2008). Stabilizing an Unstable Economy . McGraw-Hill.

Piketty, T. (2014). Capital in the Twenty-First Century . (A. Goldhammer, Trans.) (First Edition edition). Cambridge Massachusetts: Belknap Press.

Public Works and Economic Development Act of 1965, 42 U.S.C. 3121 (1965). Retrieved from http://www.epw.senate. gov/pweda65.pdf

Reese, L. A., \& Fasenfest, D. (2003). Planning for Development: An Assessment of the Economic Development District Planning Process. Economic Development Quarterly, 17(3), 264-279. https://doi.org/10.1177/0891242403251904

Veblen, T. (1915). The Theory of Business Enterprise . C. Scribner's Sons.

Watts, B. R., Erickcek, G. A., Duritsky, J., O’Brien, K., Robey, C., \& Robey, J. (2011). What Should EDA Fund? Developing a Model for Preassessment of Economic Development Investments. Economic Development Quarterly, 25(1), 65-78. https://doi.org/10.1177/0891242410377084 